\title{
Clinical efficacy of paclitaxel in the treatment of mid-stage and advanced malignant gastric cancer, and effect of nursing interventions
}

\author{
Xing-Li Zhao ${ }^{1 *}$, Xiang-Ying Zhang ${ }^{2}$ and Jian-Hong Gao $^{3}$ \\ ${ }^{1}$ Oncology Dept, ${ }^{2}$ Rheumatism Dept, ${ }^{3}$ Central Laboratory, Binzhou People's Hospital, Binzhou, 256600, PR China \\ *For correspondence: Email: zhaoxlzxlzhao@163.com
}

Received: 12 April 2016

Revised accepted: 16 August 2016

\begin{abstract}
Purpose: To investigate the clinical efficacy of paclitaxel combined with additional chemotherapy for mid-stage and advanced malignant tumors, and the benefits afforded by scientific nursing.

Methods: Patients with mid-stage and advanced gastric cancer were randomly divided into test and control groups. Control group was given intravenous chemotherapy $\left(400 \mathrm{mg} / \mathrm{m}^{2}\right.$ fluorouracil and 2500 $\mathrm{mg} / \mathrm{m}^{2}$ cisplatin) and nursed conventionally, while the test group was additionally treated with $80 \mathrm{mg} / \mathrm{m}^{2}$ paclitaxel and underwent special scientific nursing. Clinical effects and changes in the rates of apoptosis and cell proliferation were recorded. The effect of applying scientific nursing on therapeutic outcomes was also evaluated.

Results: The overall rate of treatment effectiveness, clinical control rate, mean apoptosis and proliferation rates in the test group were 56.40, 92.30, (7.10 \pm 3.17 and $28.70 \pm 3.22 \%$, respectively, while, in the control group, the values were 38.50, 64.10, $25.40 \pm 2.67$ and $32.60 \pm 2.93 \%$, respectively. The differences were all statistically significant $(p<0.05)$. In terms of nursing efficacy, the test group had a lower pain score and higher quality-of-life scores (Karnofsky performance status score) than control group. There was no significant difference in the incidence of adverse reactions between the two groups $(p>0.05)$.

Conclusion: Paclitaxel has a significant effect when used to treat mid-stage and advanced gastric cancer. Moreover, additional nursing not only enhances the therapeutic effect but also improves prognosis and quality-of-life.
\end{abstract}

Keywords: Paclitaxel, Mid-stage/advanced cancer, Gastric cancer, Nursing efficacy, Karnofsky performance status, Quality of life, Pain score

Tropical Journal of Pharmaceutical Research is indexed by Science Citation Index (SciSearch), Scopus, International Pharmaceutical Abstract, Chemical Abstracts, Embase, Index Copernicus, EBSCO, African Index Medicus, JournalSeek, Journal Citation Reports/Science Edition, Directory of Open Access Journals (DOAJ), African Journal Online, Bioline International, Open-J-Gate and Pharmacy Abstracts

\section{INTRODUCTION}

A malignant tumor is formed by constant differentiation and proliferation of cells induced by mutation; one reason why a malignant tumor recurs after treatment is that cancer cells not only invade and damage surrounding tissues and organs but also move from the primary site to other organs [1,2]. The principal conventional clinical treatments for malignant tumors are surgery, chemotherapy, and radiotherapy [3,4]. Chemotherapy occupies an important position in tumor treatment; properly selected chemotherapeutics achieve good clinical effects and even cure some malignant tumors [5]. Today, concurrent chemotherapy and radiotherapy has gradually become the standard mode by which to treat tumors. Given the continual development of anti-cancer drugs and new chemotherapeutics, ever more therapeutic 
regimens have emerged; the process continues [6].

Paclitaxel is a novel anti-cancer drug extracted from the bark or needles of Taxus chinensis. In the time since the drug was approved for marketing by the Food and Drug Administration of the United States, in 1992, it has exhibited useful clinical effects and has been extensively employed to treat various malignant tumors [7]. Paclitaxel has attracted the attention of clinical physicians. Paclitaxel is derived from plants and exerts good clinical effects with only mild side effects when combined with cisplatin. However, traditional paclitaxel preparations can induce severe adverse reactions, including allergic reactions and neurotoxicity. This compromises safety and effectiveness. Hence special monitoring and nursing is needed during treatment [8]. We selected 156 patients with midstage and advanced gastric cancer who underwent treatment in Binzhou People's Hospital, Shandong, China. We explored the effects of paclitaxel on mid-stage and advanced malignant tumors, using varied nursing methods. We hoped that such clinical experiments would yield precise guidance on how to develop a useful, clinically therapeutic regimen.

\section{METHODS}

\section{General data}

One hundred and fifty-six patients (96 males and 60 females) with mid-stage and advanced gastric cancer who underwent treatment in Binzhou People's Hospital, Shandong, China, from June 2012 to June 2014, were selected. All patients met the following inclusion criteria: pathohistological or cytological confirmation of category III or IV mid-stage or advanced gastric cancer using the TNM Staging of Malignant Tumor guidelines (2002 version); age 18 - 70 years; absence of any serious abnormality upon routine blood and urine testing; a normal electrocardiograph; normal liver and kidney functions; no chemotherapy in the past 30 days; no severe adverse reaction to chemotherapy; a KPS score of 50 or higher; a survival expectation of 12 weeks or longer; and a commitment to postoperative follow-up and co-operation. The patients were divided into test and control groups (78 in each group). In the test group, 42 patients were males and 36 females, of mean age 39.40 \pm 2.80 years; 34 were category III and 44 category IV; the mean KPS score was $59.60 \pm$ 2.70; and the numeric rating scale (NRS) indicated that 12 patients had mild pain (1 - 4 points), 46 medium pain (5 - 6 points), and 20 severe pain (7 - 9 points). In the control group, 38 patients were males and 40 females, of mean age of $36.90 \pm 3.10$ years; 40 patients were category III and 38 category IV; the mean KPS score was $61.40 \pm 2.20$; and the numeric rating scale indicated that 18 patients had mild pain (1 4 points), 44 medium pain (5 - 6 points), and 16 severe pain (7 - 9 points). None of age, gender, TNM stage, KPS score, or pain score differed significantly between the two groups; hence, the results could be compared. The study was approved by the Ethics Committee of Binzhou People's Hospital (approval no. BPH20150328ZXL) and it followed guidelines of Declaration of Helsinki [9].

\section{Therapeutic method}

Patients in the control group were given a serotonin receptor antagonist to prevent gastrointestinal reactions and then placed on pumped intravenous drips of cisplatin $(25 \mathrm{mg} /$ $\mathrm{m}^{2}$ ) for 3 days ( $3 \mathrm{~h}$ each day); 5 - fluorouracil $\left(400 \mathrm{mg} / \mathrm{m}^{2}\right)$ for 1 day $(2 \mathrm{~h})$; and 5 -fluorouracil $\left(2500 \mathrm{mg} / \mathrm{m}^{2}\right)$ for $70 \mathrm{~h}$. Patients in the test group were additionally given intravenous dexamethasone (15 $\mathrm{mg}$ for 3 days) stopping 1 day before chemotherapy, and paclitaxel (80 $\mathrm{mg} / \mathrm{m} 2$ ) for 8 days ( $3 \mathrm{~h}$ each day). Each treatment cycle lasted for 3 weeks. Clinical effects and safety were evaluated after two treatment cycles.

\section{Nursing methods}

Patients in the control group were conventionally nursed. They were given basic information on chemotherapy to reduce anxiety, and histories of drug allergies and heart disease were taken before surgery. Electrocardiography and imaging were performed and the liver and kidney functions evaluated. Patients were instructed to take drugs as prescribed by their doctors.

Patients in the test group received individualized scientific nursing including psychological care, nutritional care, care of veins, and amelioration of toxic and side-reactions. Patients were encouraged to participate positively in healthy nursing, as follows. In terms of psychological nursing, patients with mid-stage and advanced tumors are scared of chemotherapy and worry about intolerable pain or deterioration of their disease. To stabilize emotions, improve confidence in treatment, and allow uneventful completion of chemotherapy regimens, nursing staff patiently informed patients and their family members about treatment effects, toxicities, and side-effects; and explained what needed attention during treatment. In terms of nutritional 
nursing, patients undergoing chemotherapy commonly experience adverse gastrointestinal reactions. Patients were given anti-emetics to significantly relieve the symptoms of emesis and nausea. Moreover, the indoor environment was kept clean and quiet. Patients were given effective guidance on healthy diet and rest. Readily digestible, nutritional food was recommended; greasy, spicy, or irritating food was not. Blood electrolyte levels were measured in patients with severe emesis and supplementary electrolytes given by intravenous infusion if necessary. Veins also received nursing care.

Chemotherapy of a malignant tumor takes a long time; repeat puncturing and irritation of blood vessels by the drugs cause pain. Hence, we placed peripheral central catheters to reduce pain and to effectively reduce the toxicity and side effects associated with drug leakage onto the skin. The final nursing measure applied sought to minimise toxicity and side-reactions. The major toxic side-reactions of paclitaxel are reductions in leukocyte and neutrophil granulocyte counts. If leukocyte numbers decreased, patients were placed in protective isolation to prevent iatrogenic infection. Also, antibiotics were given if necessary. To prevent allergic reactions, patients took $10 \mathrm{mg}$ dexamethasone $12 \mathrm{~h}$ and $6 \mathrm{~h}$ before treatment, and also $400 \mathrm{mg}$ cimetidine and $10 \mathrm{mg}$ dexamethasone $30 \mathrm{~min}$ before treatment. All patients were also given $40 \mathrm{mg}$ diphenhydramine intramuscularly.

\section{Indices of therapeutic effects}

Clinical effects: Short-term clinical effects were divided into complete remission (CR), partial remission (PR), stable disease (SD), and progressive disease (PD) according to the Response Evaluation Criteria in Solid Tumors (RECIST) $(\mathrm{CR}+\mathrm{PR}=$ overall effective rate; $\mathrm{CR}$ $+\mathrm{PR}+\mathrm{SD}=$ clinical control rate). Apoptosis of cancer cells was measured using the terminal dexynucleotidyl transferase (TdT)-mediated dUTP nick end-labeling (TUNEL) method, and proliferation rates were measured employing the streptavidin peroxidase method. The Criteria for
Acute and Subacute Toxic Reactions of Antitumor Drugs formulated by the WHO were used to grade adverse reactions developing after chemotherapy (category 0 - IV) [10].

Nursing effects: Pain severity was evaluated with the NRS; quality-of-life with the QLQ-STO22 and the Quality-of-Life Questionnaire-Core OLQ-C30 developed by the European Organisation for Research and Treatment of Cancer (EORTC) to assess patients with gastric cancer. Clinical status after chemotherapy was evaluated by calculating Karnofsky performance status (KPS) scores [11].

\section{Statistical analysis}

SPSS version 19.0 was used to analyse all data, which were expressed as mean \pm SD. Data were compared using Student's t-test. Categorical variables were compared with the aid of Chisquared test. A difference was considered significant at $p \leq 0.05$ level.

\section{RESULTS}

\section{Clinical effects}

The overall effectiveness, the clinical control rate, and the apoptosis and proliferation rates of the test group were $56.40 \%, 92.30 \%,(27.10 \pm 3.17)$ $\%$ and $(28.70 \pm 3.22) \%$ respectively; while in the control group, the figures were $38.50 \%, 64.10$ $\%,(25.40 \pm 2.67) \%$ and (32.60 \pm 2.93$) \%$ respectively. All between-group differences were statistically significant $(p<0.05)$; the clinical outcome of the test group was better than that of the control group. The details are shown in Table 1.

\section{Adverse reactions}

Table 2 shows that the difference in the incidence of adverse reactions between the two groups was not remarkable $(p>0.05)$, suggesting that paclitaxel in combination with scientific nursing reduced the incidence of adverse reactions to a relatively low level.

Table 1: Comparison of the short-term curative effects between the two groups

\begin{tabular}{|c|c|c|c|c|c|c|c|c|c|}
\hline Group & $\mathbf{N}$ & $\begin{array}{c}\text { Proliferation } \\
\text { rate }(\%)\end{array}$ & $\begin{array}{l}\text { Apoptosis } \\
\text { rate (\%) }\end{array}$ & CR (n) & PR (n) & SD (n) & PD (n) & $\begin{array}{l}\text { Clinical } \\
\text { control } \\
\text { rate }(\%)\end{array}$ & $\begin{array}{l}\text { Overall } \\
\text { effective } \\
\text { rate }(\%)\end{array}$ \\
\hline Control & 78 & $32.60 \pm 2.93$ & $25.40 \pm 2.67$ & 4 & 11 & 10 & 14 & 64.10 & 38.50 \\
\hline Test & 78 & $28.70 \pm 3.22$ & $27.10 \pm 3.17$ & 7 & 15 & 14 & 3 & 92.30 & 56.40 \\
\hline$x^{2}$ & & 6.774 & 6.378 & 7.826 & 6.164 & 5.925 & 9.927 & 10.117 & 9.807 \\
\hline$P$ & & 0.020 & 0.023 & 0.019 & 0.028 & 0.030 & 0.003 & 0.002 & 0.005 \\
\hline
\end{tabular}


Table 2: Incidence of adverse reactions

\begin{tabular}{|c|c|c|c|c|c|c|c|c|}
\hline \multirow[b]{2}{*}{$\begin{array}{l}\text { Category of adverse } \\
\text { reaction }\end{array}$} & \multicolumn{4}{|c|}{ Test group (N) } & \multicolumn{4}{|c|}{ Control group (N) } \\
\hline & $\begin{array}{l}\text { Catego } \\
\text { ry } 0\end{array}$ & $\begin{array}{c}\text { Level } \\
\text { I-II }\end{array}$ & $\begin{array}{l}\text { Level } \\
\text { lii-IV }\end{array}$ & Incidence & $\begin{array}{l}\text { Categor } \\
\text { y } 0\end{array}$ & $\begin{array}{c}\text { Level } \\
\text { I-II }\end{array}$ & $\begin{array}{l}\text { Level } \\
\text { III-IV }\end{array}$ & Incidence \\
\hline Anemia & 46 & 22 & 10 & $41.00 \%$ & 42 & 20 & 16 & $46.20 \%$ \\
\hline Mucositis & 48 & 12 & 18 & $38.50 \%$ & 50 & 12 & 16 & $35.90 \%$ \\
\hline $\begin{array}{l}\text { Reduced leukocyte } \\
\text { numbers }\end{array}$ & 52 & 10 & 16 & $33.30 \%$ & 48 & 18 & 12 & $38.50 \%$ \\
\hline Nausea and vomiting & 40 & 24 & 14 & $48.70 \%$ & 40 & 24 & 14 & $48.70 \%$ \\
\hline Diarrhea & 38 & 20 & 10 & $38.50 \%$ & 36 & 22 & 20 & $53.80 \%$ \\
\hline Baldness & 38 & 28 & 12 & $51.30 \%$ & 34 & 28 & 16 & $58.40 \%$ \\
\hline Infection & 36 & 8 & 14 & $53.80 \%$ & 32 & 24 & 22 & $58.90 \%$ \\
\hline $\begin{array}{l}\text { Abnormal, liver, and } \\
\text { kidney problems }\end{array}$ & 28 & 32 & 18 & $64.10 \%$ & 34 & 18 & 26 & $56.40 \%$ \\
\hline
\end{tabular}

Table 3: Comparison of nursing effects between the groups

\begin{tabular}{lccccccc}
\hline Group & $\mathbf{n}$ & $\begin{array}{c}\text { Mild pain } \\
(\mathbf{n})\end{array}$ & $\begin{array}{c}\text { Medium } \\
\text { pain }(\mathbf{n})\end{array}$ & $\begin{array}{c}\text { Severe } \\
\text { pain }(\mathbf{n})\end{array}$ & QLQ-STO22 & QLQ-C30 & KPS score \\
\hline Control & 78 & 44 & 16 & 18 & $45.07 \pm 5.12$ & $52.32 \pm 4.74$ & $68.20 \pm 1.70$ \\
Test & 78 & 54 & 18 & 6 & $23.74 \pm 3.72^{*}$ & $26.33 \pm 2.47^{*}$ & $77.40 \pm 2.40$ \\
\hline${ }^{*}$ indicates $p<0.05$ on comparison of the test and control groups & & &
\end{tabular}

\section{Comparison of nursing effects}

Patient quality-of-life was also measured after chemotherapy. The pain and KPS scores of the two groups were compared. The incidence of severe pain was less in the test than the control group, and the quality-of-life scores of the test group were significantly superior to those of the control group. The details are shown in Table 3.

\section{DISCUSSION}

In this study, we selected patients with mid-stage and advanced gastric cancer and evaluated the effects of paclitaxel by forming test and control groups.

Gastric cancer is a common malignancy in China and is the principal cause of tumor-related death. Chinese patients with mid-stage and advanced gastric cancer are under particular threat. The 5year survival rate of Chinese patients with advanced gastric cancer is only $10-40 \%$. For those with mid-stage and advanced gastric cancer, chemotherapy is the major mode of therapy $[15,16]$. In the present study, the clinical outcome of the test group was significantly better than that of the control group. It is known that 5 fluorouracil inhibits tumor cell division by blocking DNA synthesis and replication, and paclitaxel biomedically modulates the effect of 5 flurouracil when given in combination with that and another drug. Therefore, the combination of a platinum-based drug, fluorouracil, and paclitaxel has become the mainstay chemotherapy for mid-stage and advanced tumors.
Paclitaxel, a phytogenic anti-carcinogen, extracted from the bark of Taxus brevifolia or Taxus chinensis, inhibits cell division at the G2-M stage by stabilising tumor cell microtubules, thus inhibiting the growth of tumor cells $[17,18]$. Paclitaxel is an anti-cancer drug with valuable effects; however, its mode of action, toxicities, and side effects differ from those of other antitumor drugs $[19,20]$. Therefore, special monitoring and nursing are needed for patients receiving paclitaxel.

Combined chemotherapy regimens dominated by paclitaxel have been tested as treatments of midstage and advanced tumors; the problems observed included high incidences of lifethreatening adverse reactions and severe allergic reactions. In the present study, the test group (receiving paclitaxel) did not experience a remarkably greater frequency of adverse reactions than the control group. This may be because careful nursing of patients under combined treatment effectively reduces the incidence of medication-induced adverse reactions. Our nursing method was effective. Moreover, the quality-of-life index scores of the test group were much higher than those of the control group.

\section{CONCLUSION}

Paclitaxel exerts a clinically valuable anti-tumor activity when used to treat mid-stage and advanced malignant tumors in combination with nutritional nursing, psychological nursing and nursing to minimize allergic reactions and 
neurotoxicity. Such nursing significantly lowers the incidence of adverse reactions, and enhances patient prognosis and quality-of-life.

\section{DECLARATIONS}

\section{Acknowledgement}

The authors wish to thank all who supported this work.

\section{Conflict of Interest}

No conflict of interest associated with this work.

\section{Contribution of Authors}

The authors declare that this work was done by the authors named in this article and all liabilities pertaining to claims relating to the content of this article will be borne by them.

\section{REFERENCES}

1. Ye M, Zhu Z, Fu Q, Shen K, Li DK. Pharmacokinetics of paclitaxel in patients with advanced ovarian cancer. Chin Pharma J 2000; 35(9): 604-606.

2. Wei Y, Duan W, Quan FS. Nursing care of patients with digestive symptoms during perichemotheraputic period. China Practical Med 2008; 3(32): 107-108.

3. Huai L, Wang HP, Cao QY. Observation and nursing of the adverse reactions of paclitaxel combined with cisplatin chemotherapy after ovarian cancer surgery. Strait Pharma J 2009; 21(11): 171-172.

4. Heys SD, Sarkar T, Hutcheon AW. Docetaxel as adjuvant and neoadjuvant treatment for patients with breast cancer. Expert Opin on Pharma 2004; 5(10): 2147-2157.

5. $Y u$ JP, Ni XC, Zhang XG, Wang J, Li Y, Hu LY, Sun ZQ, Sun SP. The response and toxicity of paclitaxel liposomes plus cisplatin combined with radiotherapy for patients with malignant tumors. Chin $J$ of Clin Rational Drug Use 2009; 2(23): 14-16.

6. Chen YG. Treatment of advanced gastric cancer: a new discovery of paclitaxel. Oncol Progress 2005; 3(4): $367-$ 373.
7. Sun $X R$, Sun $Y$. Paclitaxel in the treatment of non-small cell lung cancer. Chin J of New Drugs 1996; 5(4): 245247.

8. Chen $Q$, Zhang QZ, Liu J, Li LQ, Zhao WH, Wang YJ, Zhou $Q H$, Li L. Multi-center prospective randomized trial on paclitaxel liposome and traditional taxol in the treatment of breast cancer and non-small cell lung cancer. Chin J of Oncol 2003; 25 (2): 190-192.

9. Declaration of Helsinki. The 59th World Medical Conference, 2008.

10. Cao QY, Wang HP. Nursing of ovarian cancer treated with paclitaxel and cisplatin. $J$ of Nursed Training 2011; 26(20): 1914-1916.

11. Zhang YJ. Nursing experience on tumor chemotherapy patients. Strait Pharma J 2009; 21(8): 163-164.

12. Zhou XH, Wei X, Huang ZS, Cen C, Yin $Y X$, Qin $Y Q$, Su $Q B$. Effects of matrine on proliferation and telomerase activity of colon cancer SW1116 cells. Zhong Yao Cai 2009; 32(6): 923-925.

13. Geng $L$, Chen $X B$, Chen QJ, Chen BB. Effect and mechanism of paclitaxel liposome and paclitaxel neoadjuvant chemotherapy on breast cancer. Shandong Medi J 2011; 51(33): 89-90

14. Cao CX, Ying XM, Wang ZH, Sun J. Application of PICC in chemotherapy. Jilin Medi J 2009; 30(18): 2108-2109.

15. Wang GT. Thinking and experience in combined treatment of traditional Chinese medicine and western medicine for late gastric cancer. New $J$ of Traditi Chin Medi 2000; 32(9): 3-5.

16. Jin BL. New advances in chemotherapy of internal medicine for gastric cancer. J of Clini Res 2003; 20(10): 735-738.

17. Chen $Y Z$, Chen $K Z$, Zeng JJ. Observation and nursing of paclitaxel in the treatment of tumor chemotherapy. $J$ of Qilu Nursing 2009; 15(7):49-50.

18. Lu HM, Jiang YQ. Role of clinical pharmacists in rational use of anti-tumor drugs. Strait Pharma J 2010; 22(10): 195-196.

19. Zhang TR. Clinical efficacy of paclitaxel plus cisplatin chemotherapy combined with paclitaxel intraperitoneal perfusion in the treatment of advanced ovarian cancer. Shandong Medi J 2010; 50(45): 62-63.

20. Zhang $X J$, Zhang $P$. Advances in clinical research and development of new form of paclitaxel. Oncol Progress 2007; 5(1): 66-72. 